\title{
Risco da base e sua volatilidade no comércio de soja em Mato Grosso (2009 a 2019) ${ }^{1}$
}

\author{
Basis risk and its volatility on the soya trade at Mato Grosso \\ (2009 to 2019)
}

Felipe Parmeggiani Nardino (D), Adriano Marcos Rodrigues Figueiredo ${ }^{2}$ (1)

${ }^{1}$ Faculdade de Economia, Programa de Pós-graduação em Economia, Universidade Federal de Mato Grosso (UFMT), Cuiabá (MT), Brasil. E-mail: fpnardino25@gmail.com

Escola de Administração e Negócios, Universidade Federal de Mato Grosso do Sul (UFMS), Campo Grande (MS), Brasil. E-mail: adriano.figueiredo@ufms.br

\begin{abstract}
Como citar: Nardino, F. P., \& Figueiredo, A. M. R. (2022). Risco da base e sua volatilidade no comércio de soja em Mato Grosso (2009 a 2019). Revista de Economia e Sociologia Rural, 60(3), e240267. https://doi.org/10.1590/18069479.2021 .240267
\end{abstract}

Resumo: Esta pesquisa analisa a volatilidade da base em hedges de soja nos municípios de Mato Grosso (Sorriso, Sapezal, Rondonópolis, Nova Mutum e Querência) com os preços futuros dos contratos com vencimento em janeiro, março e maio comercializados em Chicago, no período de 2009 a 2019. A abordagem teórica análoga à teoria de estocagem avaliou o comportamento da base e as diferenças entre as bases no plantio e na maturação dos futuros, visando identificar a existência de padrões de ganhos ou perdas de base, bem como os períodos que os otimizam. A teoria de convergência entre preços futuros e à vista na maturidade do contrato não se confirmou; em geral, existem perdas de base e a base não permanece em seus valores históricos, conforme apontado em literaturas norte-americanas para a soja. Para contratos com vencimento em janeiro e março, quanto mais próximo do vencimento do contrato, maior a perda oriunda do diferencial de bases, diferentemente do contrato de maio.

Palavras-chave: commodity, preços à vista, preços futuros, risco de base, hedge.

\begin{abstract}
This research analyzes the basis volatility in soybean hedges in the municipalities of Mato Grosso (Sorriso, Sapezal, Rondonópolis, Nova Mutum, and Querência) with the contracts' future prices maturing in January, March, and May traded in Chicago, in the period of 2009 to 2019. The theoretical approach analogous to the inventory theory evaluated the behavior of the basis and the differences between the basis in the planting and the maturation of the futures, aiming to identify the existence of patterns of basis gains or losses, as well as the periods that optimize them. The theory of convergence between future and spot prices at contract maturity has not been confirmed; in general, there are basis's losses and the basis does not remain in its historical values, as pointed out in North American literature for soybeans. For contracts maturing in January and March, the closer to the maturity of the contract, the greater the loss from the basis differential, unlike the May contract.
\end{abstract}

Keywords: commodity, spot prices, future prices, basis risk, hedge.

\section{Introdução}

As commodities agrícolas apresentam grande influência na formação do produto interno bruto brasileiro. Em 2018, de acordo com os dados do Centro de Estudos Avançados em Economia Aplicada (2019), da Escola Superior de Agricultura Luiz de Queiroz (Esalq)/Universidade de São Paulo (USP), em parceria com a Confederação da Agricultura e Pecuária do Brasil (CNA), considerando o PIB-volume do agronegócio², as commodities agrícolas representaram, em

\footnotetext{
Os autores agradecem a três avaliadores anônimos pelas sugestões, assim como aos soberianos pelas válidas contribuições nos debates realizados.

2 "O agronegócio é entendido como a soma de quatro segmentos: insumos para a agropecuária, produção agropecuária básica, ou primária, agroindústria (processamento) e agrosserviços. A análise desse conjunto de segmentos é feita para o ramo agrícola (vegetal) e para o pecuário (animal). Ao serem somados, com as devidas ponderações, obtém-se a análise do agronegócio" (Centro de Estudos Avançados em Economia Aplicada, 2019).
} 
média, nos últimos 23 anos $24,5 \%$ do produto interno bruto do país, o equivalente a 1,35 trilhão de reais.

Os dados disponibilizados pelo Departamento de Agricultura dos Estados Unidos (USDA) (United States Department of Agriculture, 2019), para a safra 2018/2019, evidenciaram que dos 362 milhões de toneladas de soja produzidas no mundo, 117 milhões toneladas correspondem à produção brasileira, colocando o país em segundo lugar no ranking dos maiores produtores mundiais da oleaginosa, atrás apenas dos Estados Unidos, com 124 milhões de toneladas produzidas. Para o mesmo período, a Companhia Nacional de Abastecimento (2019) registrou a expectativa, para o estado de Mato Grosso em sua continental área de produção, de 9,7 milhões de hectares, uma produção equivalente a 32,45 milhões de toneladas, sendo o maior produtor brasileiro do grão com representatividade de $28,2 \%$ da produção nacional.

Waquil et al. (2010), em seus estudos sobre mercados e comercialização de produtos agroindustriais, ressaltaram que a agropecuária terá que conviver nas próximas décadas com o aumento dos riscos, tanto de produção quanto de mercado. Os riscos de produção estão relacionados às adversidades decorrentes das novas dinâmicas do clima oriundas do aumento das temperaturas mundiais. Por sua vez, os riscos de mercado são aqueles correlacionados à volatilidade e às tendências de preço das commodities no mercado mundial, em razão da influência de um conjunto de fatores que alteram as condições de oferta e demanda. Esse cenário exigirá dos agricultores, nas próximas décadas, aumento da utilização de instrumentos de gestão de riscos climáticos e de preço, como seguros agrícolas e mercado de derivativos.

Em meio a um ambiente de incertezas, o mercado de contratos futuros (derivativos) e a termo surgem como alternativas que possibilitam a administração e redução dos riscos de mercado, permitindo melhor planejamento, diminuição dos custos de transação e aumento na competitividade das cadeias. Entre as alternativas disponibilizadas nesse mercado, a mais comum delas é o hedge ${ }^{3}$, que, para Marques et al. (2006), pode ser definido como o ato de tomar no mercado futuro uma posição oposta àquela no mercado físico. Em outras palavras, esse instrumento tem por objetivo administrar o risco inerente à atividade. Em teoria, quando eliminado todo o risco entre o ativo físico e o contrato comercializado no mercado futuro (ativo subjacente), o hedge é denominado de hedge perfeito. No entanto, os estudos de Hull (2012) afirmam que esse tipo de estrutura é raramente encontrado, introduzindo o que vem a ser a imperfeição inerente às alternativas de hedge.

Com o passar do tempo, os preços spot ${ }^{4} \mathrm{e} o$ do contrato futuro para um mês específico não necessariamente variam na mesma proporção. Como resultado, a base muda. É justamente a incerteza implícita à diferença entre as bases, isto é, a diferença entre o preço spot e o preço da commodity no mercado futuro ao longo de um determinado período, que se denomina de risco de base.

Taylor et al. (2014) analisaram o efeito do crescimento da volatilidade da base no mercado de trigo em Kansas, nos Estados Unidos. Sanders \& Baker (2012), Bekkerman \& Pelletier (2009) e Stringer \& Sanders (2006) ressaltaram a importância da análise da volatilidade da base nos mercados de soja e milho como um dos principais riscos de preços no Centro-Oeste norteamericano (especificamente, analisaram Ohio e Illinois). Mattos e Silveira (2015) estudaram alterações da base no mercado de milho brasileiro (em Cascavel [PR], Chapecó [SC], Mogiana [SP] e Rio Verde [GO]), especificamente o efeito da segunda safra sobre os preços dessa commodity. Botelho Filho \& Souza Júnior (2006) estudaram o risco de base de soja em Lucas

3 O termo hedge é derivado do verbo em inglês to hedge, que significa colocar uma cerca ou proteção ao redor de algo.

4 O preço spot é o preço à vista, ou seja, o preço comercializado para entrega imediata. 
do Rio Verde (MT) e Sinop (MT), no período de 2000 a 2005, com mais risco de base para o contrato de maio. Maia \& Aguiar (2010) estudaram hedges de soja em dez locais brasileiros no período de 2001 a 2004. Para Sorriso (MT), haveria menos risco de base, ao trabalhar médias mensais em diferentes contratos futuros. Medeiros et al. (2013) analisaram hedges para cálculo da razão ótima e efetividade para o período de 2005 a 2010 e afirmaram que o sojicultor de Sorriso (MT) estaria mais sujeito a risco comparado ao de Rio Verde (GO).

É oportuno destacar que a existência da base permeia não somente os contratos atrelados à mesma praça de comercialização de um derivativo. Pode depender também, entre outras variáveis, de vencimento, liquidez, preço de referência, cross-hedge, entre outros. Além disso, o risco de base afeta diretamente o faturamento do produtor ao realizar o hedge. Quanto maior a ineficiência dessa operação, pior será a situação para o produtor. Neste aspecto, Tomek \& Peterson (2001) mencionam a importância de se compreender o risco de base para a efetividade do hedge, na teoria de decisão de estocagem e na mitigação de riscos de preços ao produtor. O presente artigo não tem por meta realizar previsões futuras da base, mas a pergunta de pesquisa em Tomek \& Peterson (2001) era justamente saber se a base poderia ser acuradamente prevista no início do hedge, dada a importância desse conhecimento.

Portanto, operações de hedge conferem ou não proteção adequada contra a oscilação dos preços ao longo do tempo, bem como apresentam padrões de perdas ou ganhos de base na comercialização de soja de Mato Grosso? A hipótese básica é proveniente de Zulauf et al. (1999) de que as evidências (tanto empíricas como teóricas) sugerem menores variabilidades quanto mais próximas do plantio (Tomek \& Peterson, 2001, p. 962). Como muitas vezes é esperado que a base permaneça em seus valores históricos, o presente estudo evidencia que isso não é verdadeiro, assim como citado por Taylor et al. (2004).

Considerando as informações apresentadas até o momento, esta pesquisa tem por objetivo analisar a volatilidade da base em hedges de soja nos municípios ${ }^{5}$ de Nova Mutum, Sapezal, Sorriso, Querência e Rondonópolis, durante o período de 2009 a 2019. Especificamente, pretende-se avaliar a existência de padrões de ganhos ou perdas de base para os agentes que realizam operações de hedge utilizando contratos futuros comercializados na bolsa de Chicago (CME Group para Chicago Mercantile Exchange).

Espera-se que o presente trabalho contribua para o dimensionamento das possíveis perdas de base, possibilitando que essas informações sejam consideradas em futuras análises de viabilidade econômica e financeira das atividades de produção e comercialização de soja no estado de Mato Grosso.

\section{Revisão teórica sucinta}

No mercado financeiro, quando os preços futuros se encontram abaixo do preço à vista esperado para a mesma data do vencimento do contrato futuro, tal situação é denominada de normal backwardation, ao passo que quando o preço futuro se encontra acima do preço à vista esperado para a data de vencimento do contrato futuro, denomina-se Contango. Tal ponderação se faz necessária, uma vez que esses termos são utilizados para fazer referência a situações em que o preço futuro se encontra abaixo ou acima do preço à vista corrente, em vez do preço à vista esperado para a data do vencimento do contrato futuro.

${ }^{5}$ Municípios que figuram entre os sete maiores produtores do estado de Mato Grosso (Instituto Brasileiro de Geografia e Estatística, 2016) e representam quatro das sete macrorregiões do Instituto Mato-Grossense de Economia Agropecuária (IMEA), Oeste, Médio Norte, Nordeste e Sudeste (Instituto Mato-Grossense de Economia Agropecuária, 2017). 
Cootner (1960), de forma sintetizada, descreve a hipótese Keynes \& Hicks por meio do pressuposto que os hedgers utilizam os mercados futuros para evitar risco. Eles o fazem vendendo seus ativos físicos para entrega em algum momento no futuro, a um preço que cubra o seu custo de oportunidade de armazenagem. Essa oportunidade de proteção contra risco é valiosa aos hedgers e, de acordo com a arguição de Keynes, essa proteção na venda só é possível em função da disposição dos especuladores em fornecer esse "serviço" em troca de uma taxa. O especulador se empossa dessa taxa por recusar comprar o contrato de venda do hedger, exceto se este apresentar um preço inferior ao que ele espera obter próximo ao vencimento do contrato.

Hull (2012), de maneira mais abrangente, apresenta a combinação dos estudos de Keynes (1930) e Hicks (1939), que argumentam que se os hedgers tendem a manter posições de venda, enquanto os especuladores, posições de compra, os preços futuros de um ativo deverão ser menores do que o preço esperado para o ativo no mercado à vista. Isso ocorre porque os especuladores requerem uma recompensa pelo risco ao qual se submetem. Eles participarão das negociações somente se houver expectativa de ganhar dinheiro na média. Os hedgers perderão dinheiro na média, no entanto estão mais predispostos a aceitar isto, uma vez que os contratos futuros reduzem seu risco. Por outro lado, caso os hedgers tendam a assumir uma posição de compra e os especuladores, uma posição de venda, os preços futuros seriam acima do preço esperado para o mercado spot pela mesma razão.

Cootner (1960) e Hull (2012) evidenciam a esquemática de normal backwardation por meio das figuras dos traders assumindo posições de venda e dos especuladores assumindo posições de venda, inerente aos estudos de Keynes e Hicks. Kolb (1992), visando testar essa hipótese, traz à tona um compilado de obras acerca do tema, relatando que, de forma empírica, em muitos mercados, tanto produtores quanto consumidores de um bem podem figurar como hedgers. Especialmente no caso de grãos, em que os produtores rurais assumem a posição de venda para se proteger dos riscos de preço, enquanto os processadores de grãos/indústrias assumem posição de compra no mercado futuro como forma de se proteger do risco de preços.

Em seu estudo, Kolb (1992) examinou 29 commodities somando mais de 980.800 negociações diárias, por meio de uma série de preços entre o período de 1957 e 1988, sob a ótica das três mais importantes implicações da teoria de normal backwardation: 1) que o retorno dos preços futuros deve ser positivo; 2) de que os preços futuros antes do vencimento dos contratos devem ser inferiores ao preço futuro na data do vencimento do contrato; 3 ) de que a relação entre preço futuro e tempo para o vencimento do contrato é inversamente proporcional, isto é, quanto maior for o tempo para o vencimento do contrato, menor deverá ser o preço do contrato futuro. Das 29 commodities analisadas, apenas quatro séries atenderam aos três pressupostos. Cobre, algodão, soja, farelo de soja e óleo de soja atenderam parcialmente aos três pressupostos e todos falharam em pelo menos um deles. Houve também três commodities que apresentaram comportamento inverso aos pressupostos de normal backwardation, isto é, comportamento Contango. Seus retornos futuros foram negativos, os preços futuros antes do vencimento do contrato se apresentaram superiores aos do vencimento do contrato e seus preços futuros tenderão a ser maiores quanto maior o tempo para o vencimento do contrato.

Em síntese, a maioria das commodities apresentou nenhum prêmio pelo risco, retorno próximo a zero e preços antes do vencimento muito próximos aos da data de vencimento do contrato. O mais surpreendente foi que enquanto algumas commodities agrícolas apresentaram comportamento de normal backwardation e outras, comportamento Contango, a maioria não seguiu nenhum dos dois processos, não pagando nenhum prêmio pelo risco, logo evidenciando 
que o comportamento de normal backwardation não é normal, ou seja, não é um evento comum ao mercado de futuros.

A opinião média do mercado sobre qual será o preço futuro de um ativo em algum momento no futuro reflete a expectativa sobre o preço à vista do ativo naquela mesma data. Os pressupostos teóricos apontam que o preço futuro de um ativo converge para o preço à vista, à medida que o vencimento do contrato futuro se aproxima (Hull, 2012). Na hipótese de que o preço à vista esperado seja inferior ao futuro, as expectativas do mercado são de que o preço futuro para o mês de vencimento caia, fazendo com que os traders que tenham posições vendidas realizem ganhos enquanto traders posicionados em situação de compra e perdas, sendo a recíproca verdadeira.

Para Hull (2012), à medida que o período de entrega do contrato futuro se aproxima, o preço futuro converge para o preço à vista do ativo subjacente. Na data da entrega do contrato futuro, o preço futuro é igual ou muito próximo do preço à vista. Neste caso, os operadores poderão vender o contrato futuro, comprar o ativo ou realizar a sua entrega.

\section{Variabilidade da base}

Do ponto de vista da base em mercados futuros, Tomek \& Peterson (2001) destacam a importância de se compreender o risco de base para a efetividade do hedge, com base normalmente na teoria de decisão de estocagem e na mitigação de riscos de preços ao produtor. Taylor et al. (2004) mencionam o trabalho de Working (1949) como referência da teoria de decisão de estocagem.

A base enquanto a diferença entre os preços spot e futuro em um dado período seria afetada por inúmeras condições locais de oferta e demanda, estrutura de mercado, tributação, custos de estocagem e de transporte, enfim, pelos fatores que afetam os preços à vista (determinantes e deslocadores da oferta e demanda), assim como os futuros (expectativas, variáveis macroeconômicas, entre outras), em diferentes locais (mercado físico x mercado de futuros, por exemplo, Chicago para o CME Group) (Tomek \& Peterson, 2001; Hull, 2012; Feuser, 2014).

Para Tomek \& Peterson (2001), a teoria de estocagem de Working (1949) seria válida para lavouras cujos preços apresentam sazonalidade e estoques contínuos e o preço futuro menos o preço à vista no tempo t definirá o preço de estocagem para carregar o estoque entre o período t e uma data de maturação T. Assim, os diferentes preços à vista e futuros para diversas datas de maturação oferecerão incentivos ou desincentivos para a estocagem, assim como para realizar ou não proteção via hedge. Para os primeiros autores, a compreensão dos contratos futuros utilizados para hedge dos estoques, ou para a decisão dos produtores, assim como a compreensão das relações envolvidas com a base e o risco de base, é fundamental para a efetividade do hedge.

O efeito chamado de "tempo para maturação" (Hennessy \& Wahl, 1996; citado por Tomek \& Peterson, 2001, p. 961) aparece à medida que a incerteza é reduzida, uma vez tomadas as decisões e a chegada de informações mais acuradas, ou seja, a oferta e a demanda ficam mais preço inelásticas, uma vez que as decisões sejam tomadas. Por exemplo, como Tomek e Peterson (op. cit.) exemplificaram, a variabilidade do preço de um contrato futuro na maturidade se compara com a variabilidade anterior durante a vida do contrato. Por exemplo, a variabilidade ano a ano do preço do contrato de soja de vencimento em março poderá um pouco antes, diga-se em dezembro, estar diferente da variabilidade do mesmo contrato em um dezembro de um ano específico. 
Stringer \& Sanders (2006) mostram que nesse cenário o produtor enfrentará o risco de base tanto inerente ao preço futuro como à base local, devendo-se comparar a variabilidade da base na época do plantio (forward basis), assim como da época da colheita (actual basis). A análise desses autores para milho e soja em regiões de Illinois (EUA) revelou uma forward basis muito menos volátil que a base na colheita. Os autores ainda sugerem que, a cada ano, melhor conhecimento do comportamento da base permite modificar as condições locais que afetam a base.

Recorrendo à teoria de estocagem, conforme Taylor et al. (2014), o custo do produtor quando toma um contrato futuro, $C_{i, j, t^{\prime}}$ de um local $i$ no ano $j$ e semana $t$ é definido como, em que é o preço à vista na colheita no local $i$ no ano $j$; é o preço do contrato futuro do local $i$ no ano $j$ e semana $t$, é o prêmio de risco nesse contrato futuro utilizado pela cerealista do local pela exposição ao risco inerente ao contrato futuro. $\mathrm{O}$ custo incorrido nesse contrato futuro não poderá ser calculado até o tempo da colheita, 0 , quando a base atual na colheita é conhecida. Pode-se rescrever a expressão de $C_{i, j, t}$ como:

$P_{i, j}(0)=B_{i, j}(0)+\operatorname{CME}_{j}(0)$

e

$\mathrm{F}_{\mathrm{i}, \mathrm{j}, \mathrm{t}}\left(\mathrm{r}_{\mathrm{i}, \mathrm{t}}\right)=\mathrm{B}_{\mathrm{i}, \mathrm{j}, \mathrm{t}}\left(\mathrm{r}_{\mathrm{i}, \mathrm{j}, \mathrm{t}}\right)+\mathrm{CME}_{\mathrm{j}, \mathrm{t}}(0)$

em que é a base na colheita para o local ino ano j; é o valor da Bolsa de Chicago (CME Group) para o contrato futuro de soja em grão para colheita no ano $j$; é a base implícita no contrato futuro do local ino ano $j$ e semana $t$, é o valor do contrato futuro de soja no ano $j$ na semana $t$. É possível, então, expressar $C_{i, j, t}$ em termos de (1) e (2), obtendo (3) e aplicando as expectativas para determinar o resultado do contrato futuro esperado pelo produtor.

$\mathrm{C}_{\mathrm{i}, \mathrm{j}, \mathrm{t}}=\mathrm{E}_{\mathrm{j}, \mathrm{t}}\left[\mathrm{B}_{\mathrm{i}, \mathrm{j}}(0)\right]+\mathrm{E}_{\mathrm{j}, \mathrm{t}}\left[\mathrm{CME}_{\mathrm{j}}(0)\right]-\mathrm{B}_{\mathrm{i}, \mathrm{j}, \mathrm{t}}\left(\mathrm{r}_{\mathrm{i}, \mathrm{j}, \mathrm{t}}\right)-\mathrm{CME}_{\mathrm{j}, \mathrm{t}}(0)$

Neste caso, expectativas da base no período da colheita e preços futuros são condicionais ao conjunto de informações no ano $j$ e semana $t$. Os preços futuros podem ser definidos como $\mathrm{E}_{\mathrm{j}, \mathrm{t}}\left[\mathrm{CME}_{\mathrm{j}}(0)\right]=\mathrm{CME}_{\mathrm{j}, \mathrm{t}}(0)$, de tal modo que $\mathrm{C}_{\mathrm{i}, \mathrm{j}, \mathrm{t}}=\mathrm{E}_{\mathrm{j}, \mathrm{t}}\left[\mathrm{B}_{\mathrm{i}, \mathrm{j}}(0)\right]-\mathrm{B}_{\mathrm{i}, \mathrm{j}, \mathrm{t}}\left(\mathrm{r}_{\mathrm{i}, \mathrm{j}, \mathrm{t}}\right)$. Considerando um prêmio de risco aditivo da base implícita no contrato futuro, $\mathrm{r}_{\mathrm{i}, \mathrm{j}, t}$ então se tem o custo que o produtor que se utiliza de contrato futuro espera pagar, expressão (4).

$\mathrm{C}_{\mathrm{i}, \mathrm{j}, \mathrm{t}}=\mathrm{E}_{\mathrm{j}, \mathrm{t}}\left[\mathrm{B}_{\mathrm{i}, \mathrm{j}}(0)\right]-\mathrm{B}_{\mathrm{i}, \mathrm{j}, \mathrm{t}}+\mathrm{r}_{\mathrm{i}, \mathrm{j}, \mathrm{t}}$

A parte $\mathrm{E}_{\mathrm{j}, \mathrm{t}}\left[\mathrm{B}_{\mathrm{i}, \mathrm{j}}(0)\right]-\mathrm{B}_{\mathrm{i}, \mathrm{j}, \mathrm{t}}$ é a diferença entre a base esperada na colheita da semana te a base implícita no contrato futuro da semana $t$. Essa diferença será a parte essencial analisada no presente artigo, de modo que movimentos adversos na base poderão reduzir a efetividade do hedge. A diferença de base também é vista como o Embedded Cost conforme Stringer \& Sanders (2006) e permitirá a análise da variabilidade da base, conforme Taylor et al. (2014).

\section{Método e dados}

Para este estudo, foram coletadas as séries históricas semanais de preços da saca de $60 \mathrm{~kg}$ de soja dos principais municípios produtores de soja em Mato Grosso, no período de 2009 a 
2019, por meio do Imea. Em função de sua representatividade da produção da oleaginosa para o estado de Mato Grosso, os municípios escolhidos foram Nova Mutum, Sorriso, Sapezal, Querência e Rondonópolis, que, considerando o Mapa de Macrorregiões de Mato Grosso, publicado pelo IMEA (Instituto Mato-Grossense de Economia Agropecuária, 2017), representam as macrorregiões Médio Norte, Oeste, Nordeste e Sudeste, respectivamente.

As cotações de fechamento Ptax4 do dólar dos Estados Unidos disponíveis no Banco Central do Brasil foram utilizadas para conversão das séries de preços spot nominais dos munícipios de Mato Grosso. Aplicando as cotações da série de dólar norte-americano nas séries de preços spot para os munícipios de Mato Grosso abordados neste estudo, foi possível convertê-las de reais por saca de 60 quilos para dólares por saca de 60 quilos

Considerando que as cotações dos contratos futuros utilizados para as operações de hedge pelos agentes do agronegócio de Mato Grosso são aquelas listadas na Bolsa de Chicago, a evolução das séries históricas dos preços nominais em centavos de dólar por Bushel disponíveis pela Chicago Mercantile Exchange (CME Group, 2019) foi compilada e, em detrimento da necessidade de equalização das unidades de medidas e monetárias, as séries históricas de preço dos contratos futuros comercializadas na Bolsa de futuros de Chicago foram convertidas de $\zeta$ CUS/Bushel para US\$/saca de $60 \mathrm{~kg}$. Como a unidade monetária elegida para o estudo foi dólares norte-americanos, para que as séries históricas das cotações, tanto dos futuros listados em Chicago quanto do preço spot para os municípios de Mato Grosso listados neste estudo, pudessem refletir o valor de compra da data do estudo, utilizou-se o índice de preços ao consumidor norte-americano para inflacionar as cotações.

\subsection{Consolidação dos dados e análise descritiva das bases}

Seguindo a metodologia aplicada por Feuser (2014), foi considerado que a decisão de fazer a operação de hedge ocorreria a partir de setembro de cada mês, quando normalmente se inicia o período de preparação do solo para o plantio. Portanto, no intuito de padronizar as datas em que as operações de travamento dos preços começam a ser realizadas, considerou-se um período de dez semanas (compreendendo apenas de segunda-feira a sexta-feira, excluindo sábados e domingos) a partir da primeira segunda-feira do mês de setembro de cada ano. Logo, a última data para iniciar o travamento dos preços ocorreria na sexta-feira da décima semana após a primeira segunda-feira do mês de setembro de cada ano.

Da mesma forma, o período de encerramento da posição também foi dividido em dez semanas (compreendendo apenas de segunda-feira a sexta-feira, excluindo sábados e domingos), sendo a última semana aquela que contém o último dia de comercialização dos contratos futuros na Bolsa de Chicago e a primeira data de encerramento a segunda-feira da nona semana que antecede a semana do vencimento do contrato futuro.

Considerando que temos 50 possíveis datas para início das operações de hedge (dez semanas a partir da primeira segunda-feira de setembro cinco dias úteis por semana) e 50 possíveis datas para encerramento das operações (dez semanas antecedentes ao vencimento do contrato cinco dias úteis por semana), temos como resultado uma matriz com 2.500 observações, isto é, 2.500 possibilidades de resultado de base para cada ano estudado. Tendo em vista que o horizonte temporal do estudo compreende os anos de setembro de 2009 a maio de 2019, temos um equivalente a 25.000 possíveis valores de base ( 2.500 possibilidades ao ano horizonte temporal de dez anos-safra).

Mediante a utilização do teorema de medidas de posição central, foi possível reduzir o número de observações para os valores médios para cada uma das dez semanas de plantio e 
de encerramento dos contratos, resultando em um total de 100 cruzamentos entre semanas de plantio e de encerramento dos contratos.

As bases médias para as dez semanas de plantio foram calculadas da seguinte forma:

$\overline{\mathrm{B}_{\mathrm{n}}}=\frac{\sum_{\mathrm{i}=2 \mathrm{n}}^{\mathrm{i}=\mathrm{n}}\left(\mathrm{S}_{\mathrm{i}}-\mathrm{F}_{\mathrm{i}}\right)}{\mathrm{nc}}$

em que: $\overline{\mathrm{B}_{\mathrm{n}}}$ é a base média do município na enésima semana de plantio; $2 \mathrm{n}$ é a segunda-feira da enésima semana de plantio; 6 n é a sexta-feira da enésima semana de plantio; $\mathrm{S}$ é o preço spot; F é o preço futuro; i é a segunda, terça, quarta, quinta e sexta-feira da semana de plantio; nc é o número de dias em que houve cotações na semana antes do plantio.

Para as dez semanas de encerramento das posições, o seguinte cálculo foi realizado para a base média do município na semana (n-1) do vencimento do contrato:

$\overline{\mathrm{B}_{\mathrm{n}-1}}=\frac{\sum_{\mathrm{i}=2(\mathrm{n}-1)}^{\mathrm{i}=6(\mathrm{n}-1)}\left(\mathrm{S}_{\mathrm{i}}-\mathrm{F}_{\mathrm{i}}\right)}{\mathrm{nc}}$

em que: $\overline{\mathrm{B}_{(\mathrm{n}-1)}}$ é a base média do município na semana ( $\left.\mathrm{n}-1\right)$ do vencimento do contrato; $2 \mathrm{n}$ é a segunda-feira da (enésima-1) semana do vencimento do contrato; 6 n é a sexta-feira da (enésima-1) semana do vencimento do contrato; S é o preço spot; F. é o preço futuro; i é a segunda, terça, quarta, quinta e sexta-feira da (n-1) semana do vencimento do contrato; nc é o número de dias em que houve cotações na semana do vencimento.

De posse das duas bases (bases das j-ésimas semanas de plantio $B_{j}$ obtidas em [5] e bases próximas ao encerramento do contrato $B_{(n-1)}$ obtidas em [6]), a variação entre elas foi calculada da seguinte forma:

$\Delta \mathrm{B}_{(\mathrm{n}-1)}=\frac{\sum_{\mathrm{j}=1}^{\mathrm{j}=10}\left(\overline{\mathrm{B}_{(\mathrm{n}-1)}}-\overline{\mathrm{B}_{(\mathrm{J})}}\right)}{10}$

em que: $\Delta B_{(n-1)}$ é variação na semana (n-1) de vencimento do contrato em relação à semana de plantio; j é a semana de plantio de uma a dez semanas; $\overline{\mathrm{B}_{(\mathrm{n}-1)}}$ é a base média da semana $(\mathrm{n}-1)$ do vencimento do contrato; $\overline{\mathrm{B}_{(J)}}$ é a base média da j-ésima semana do plantio.

Realizados os cálculos das bases pelas expressões (5) a (7), foram calculados os componentes descritivos. É oportuno mencionar que este estudo compreende as operações de hedge utilizando como ativos de referência para preços futuros aqueles comercializados na Bolsa de Chicago com vencimento em janeiro (ZSFXX), março (ZSHXX) e maio (ZSKXX) (ver detalhes do código no Material suplementar A.1.1). No que diz respeito ao período de simulação dessas operações, o posicionamento no mercado futuro ocorre entre a primeira até a décima semana de plantio, enquanto a data de liquidação no mercado futuro ocorre entre a semana do vencimento do contrato em questão e a nona semana que antecede seu vencimento. A Figura 1 contém uma matriz de relacionamento entre semanas de plantio $x$ semanas de vencimento que explicita como a diferença de base média para cada período foi encontrada.

De posse das bases médias dispostas nos formatos de matrizes $10 \times 10$ conforme exposto anteriormente, um mapa de calor foi aplicado sobre estas, de sorte que quanto mais negativa a diferença de base, a coloração dos dados na matriz se aproxima da cor vermelho. Por outro lado, quanto menos negativa for a diferença da base, mais a coloração dos dados na matriz se aproxima da cor verde. 


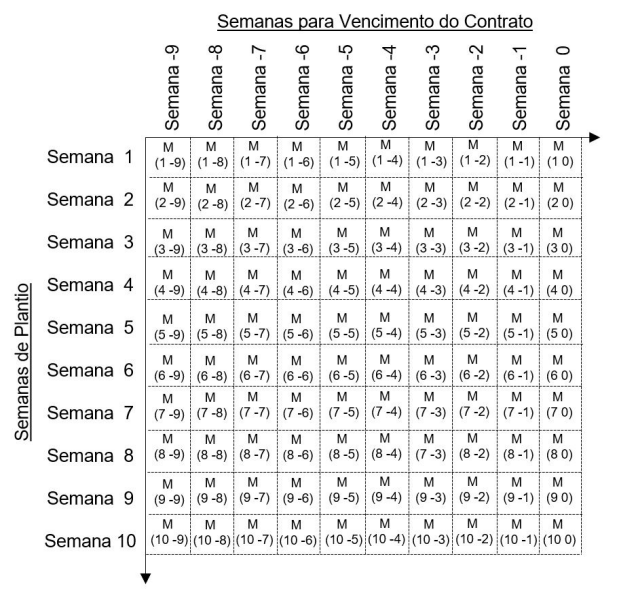

Figura 1. Matriz modelo de relacionamento entre semanas de plantio x semanas para vencimento do contrato para cálculo da diferença de base média em cada município. Fonte: elaboração própria.

\section{Resultados e discussão}

As Figuras 2 e 3 mostram, respectivamente, a evolução das séries históricas dos preços nominais da saca de 60 quilos, para os municípios de Nova Mutum, Querência, Rondonópolis, Sapezal e Sorriso, todos localizados no estado de Mato Grosso, e flutuações dos preços nominais no Mercado Futuro de Chicago, para os diferentes contratos.

De maneira geral, a evolução das séries revela forte correlação entre as localidades analisadas, gerando indícios de que os pequenos movimentos que as divergem estejam relacionados a fatores internos de formação de preços, possivelmente relacionados à logística de transporte interno.

Do ponto de vista da relação com contratos futuros, é possível avaliar a correlação entre as séries domésticas (Tabela A1 do Apêndice 1), em que os valores são todos acima de 0,78 , evidenciando a alta integração de mercados domésticos no estado. Já em relação às correlações entre os preços domésticos e os futuros, apresentaram correlações em torno de 0,63 a 0,68 (os valores mais próximos de 0,68 para Rondonópolis e os mais próximos de 0,63 para Sorriso e Nova Mutum). A série de preços para Sapezal se destaca com correlações mais fortes, da ordem de 0,8 com os preços futuros. Ocorreram correlações fortíssimas entre os valores dos contratos futuros de diferentes vencimentos $(0,95)$.

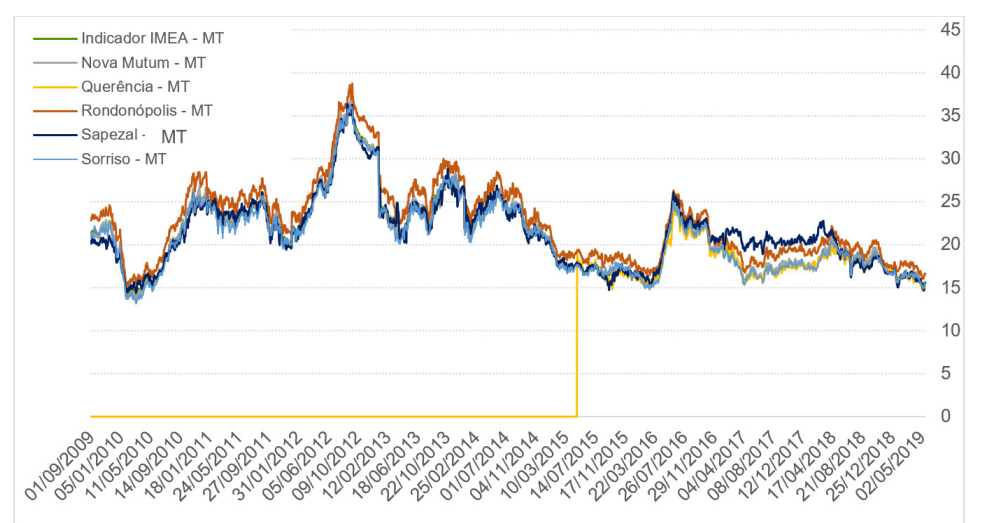

Figura 2. Evolução dos preços nominais no mercado spot dos munícipios de Mato Grosso - US\$/ saca de $60 \mathrm{~kg}$. Fonte: dados consolidados e convertidos pelos autores. 


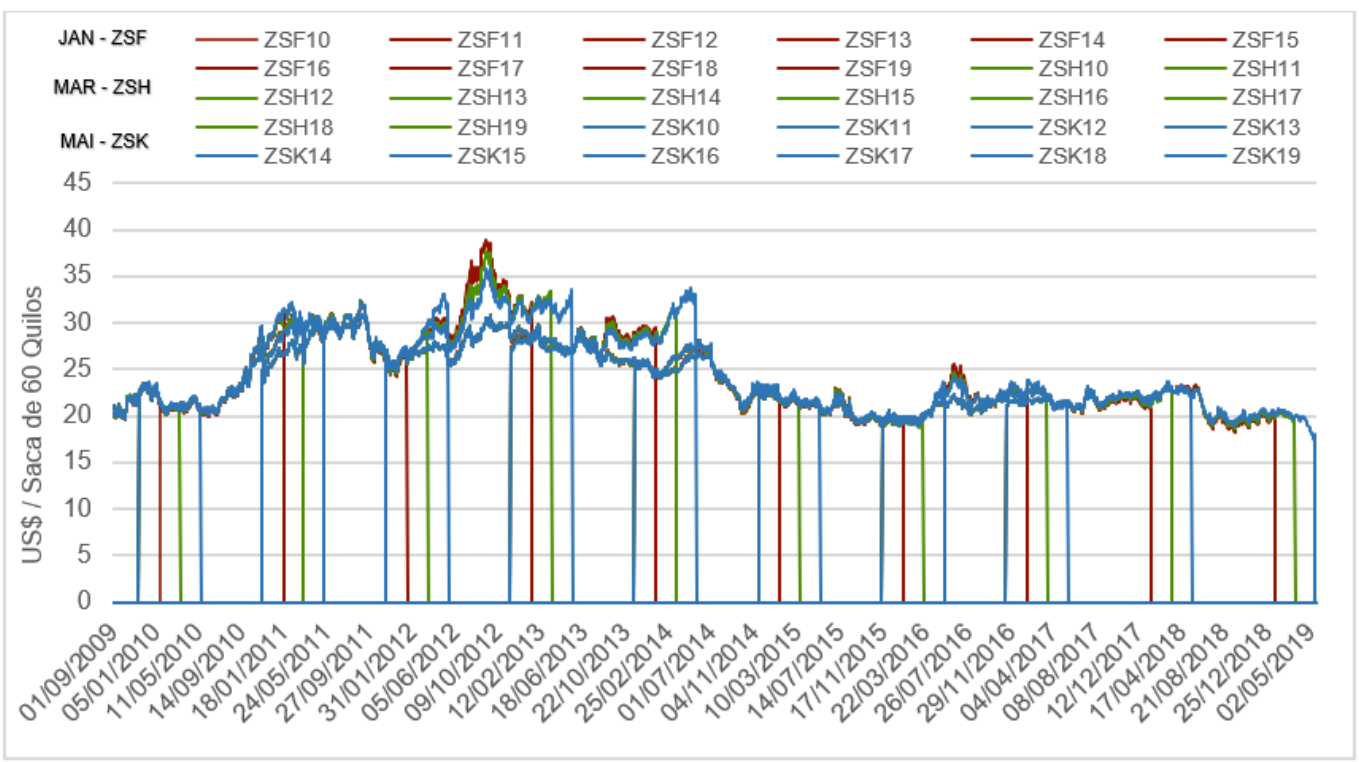

Figura 3. Evolução dos preços nominais no Mercado Futuro de Chicago; diferentes contratos - US\$/ saca de 60 kg. Fonte: conversão de dados elaborada pelos autores.

Após inflacionar as séries, calculou-se o valor da base para cada um dos munícipios objetos deste estudo (Nova Mutum [MT], Sorriso [MT], Rondonópolis [MT], Querência [MT] e Sapezal [MT]), comparando-se os valores das cotações à vista inflacionadas nessas localidades com as cotações inflacionadas dos contratos futuros com vencimento em janeiro, março e maio, negociados na Bolsa de Futuros de Chicago (CME Group), conforme exposto nas Figuras A1 a A5 do Apêndice 1.

Por meio da consolidação dos dados compilados para este estudo (pelas expressões 5, 6 e 7, seção 3.1), foi possível analisar o comportamento da base para os municípios do estado de Mato Grosso - Nova Mutum, Sorriso, Rondonópolis, Sapezal e Querência -, identificando os valores esperados de diferença de base para os agentes que comercializam a commodity nos municípios e utilizam o hedge como estratégia de proteção contra risco de preços. As estatísticas descritivas desses contratos estão no Apêndice 1 do artigo.

Na Figura 4, é possível observar que, para os municípios de Mato Grosso - Sorriso, Sapezal, Rondonópolis e Nova Mutum -, o comportamento das bases durante 2009 a 2019 apresentou um padrão muito similar. Nas simulações utilizando os contratos de janeiro e março para realização do hedge, à medida que os contratos se aproximam de seu vencimento, maior é o diferencial de bases. Já para as simulações de hedge utilizando contratos com vencimento em maio, quanto mais próximo do vencimento do contrato, menor o diferencial de bases, resultado similar a Maia \& Aguiar (2010) feito para Sorriso para 2001 a 2004.

Na Figura 4, é possível observar que o município de Querência, embora tenha apresentado tendência similar à dos demais (isto é, contratos com vencimento em janeiro e março: aumento do diferencial de bases quanto mais próximo de seu vencimento; e contrato de maio: quanto mais próximo do seu vencimento, menor o diferencial de bases), o diferencial de bases apresentou comportamento singular, apresentando picos de variação em diferentes momentos em relação aos demais municípios.

Considerando que, para Querência, o estudo foi realizado a partir de 2015, quando as cotações passaram a ser registradas pelo IMEA, as séries históricas dos demais municípios foram 
$2009-2019$

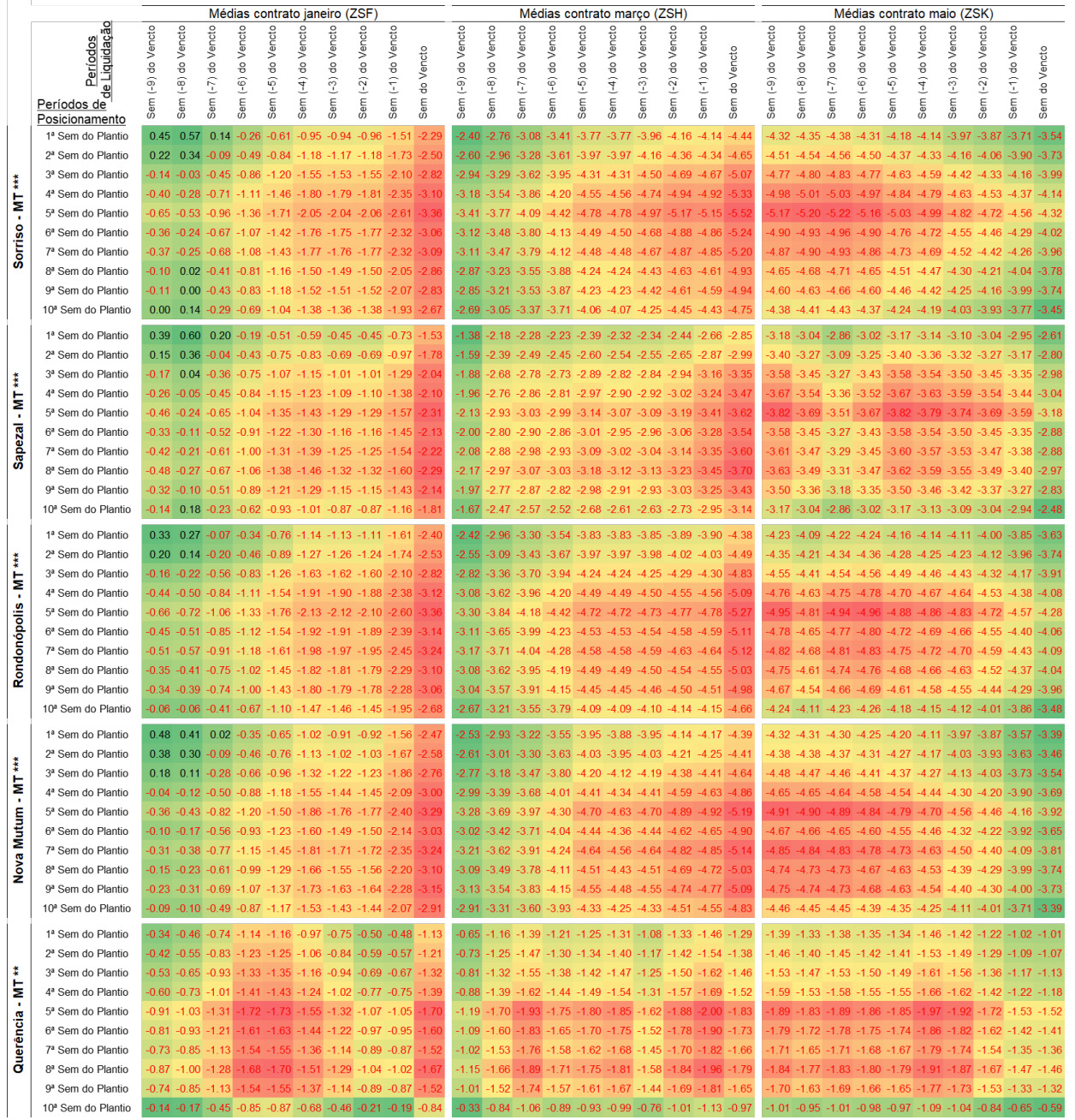

Figura 4. Diferenças de bases médias estratificadas por contrato - Horizonte temporal de 2009 a 2019. * Horizonte temporal de 2009 a 2019. ** Horizonte temporal de 2015 a 2019. Fonte: consolidação de dados. Elaboração própria.

trazidas ao mesmo horizonte temporal (2015 a 2019), para verificar se seus comportamentos se assemelhariam aos de Querência (Figura 5).

A Figura 5 mostra o comportamento do diferencial de bases considerando o horizonte temporal de 2015 a 2019. Após análise dos dados obtidos pelas séries temporais que contemplam o horizonte temporal de 2015 a 2019, observou-se que os comportamentos das bases para os municípios de Nova Mutum, Sorriso, Rondonópolis e Sapezal se ajustaram a um padrão de comportamento similar ao evidenciado anteriormente na série histórica de diferencial de bases do município de Querência, revelando o seguinte padrão de comportamento:

- Para as simulações utilizando os contratos com vencimento em janeiro, analogamente ao exposto sobre os resultados expostos na Figura 4 (para 2009-19), quanto mais próximo do vencimento do contrato, maior o diferencial de bases. Esses resultados corroboram as evidências de Zulauf et al. (1999) e Tomek \& Peterson (2001) de que há menores variabilidades quanto mais próximas do plantio. Há, no entanto, para todos os municípios entre o período 


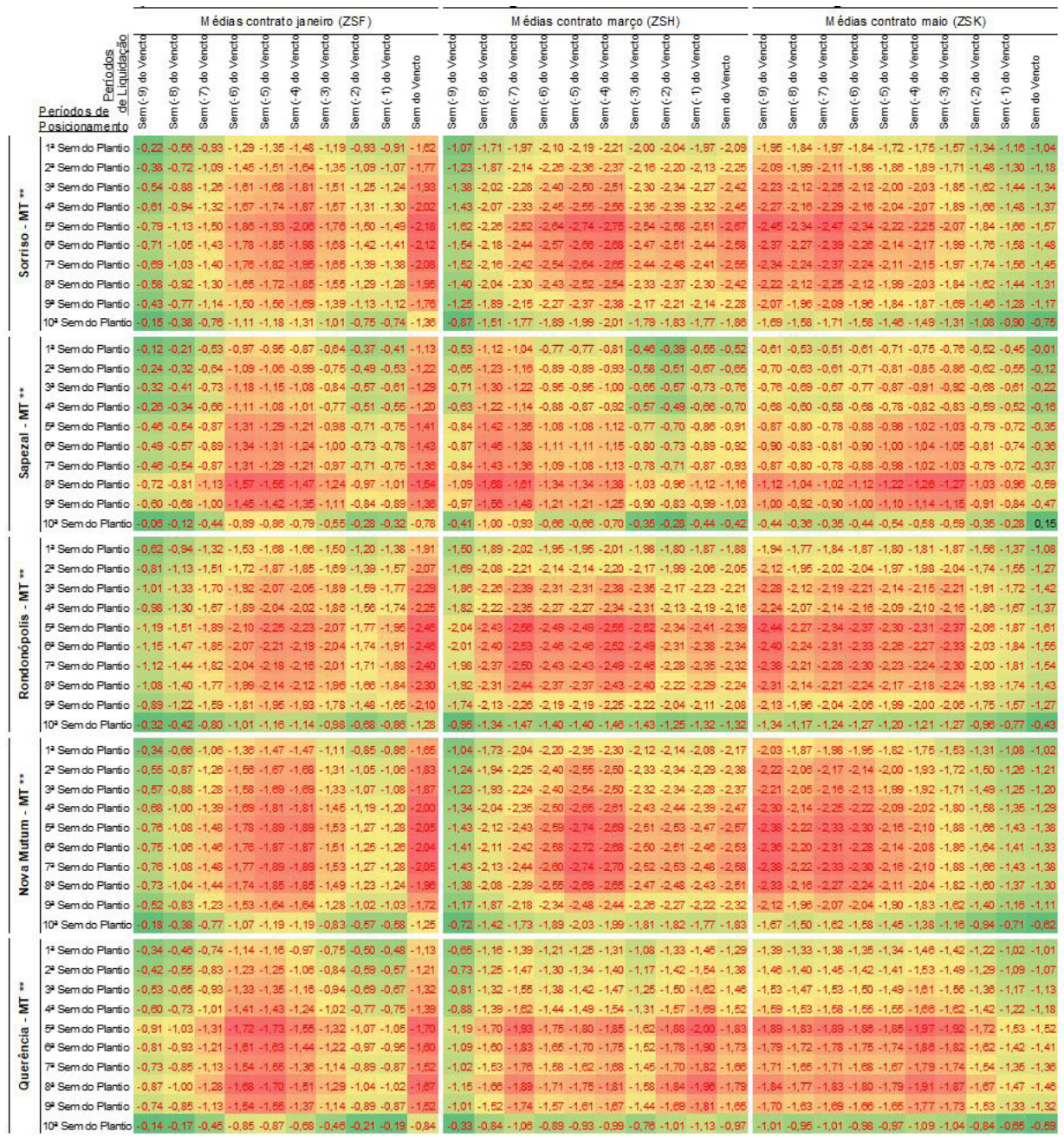

Figura 5. Diferenças de bases médias estratificadas por contrato - Horizonte temporal de 2015 a 2019. ** Horizonte temporal de 2015 a 2019. Fonte: consolidação de dados. Elaboração própria.

de seis a quatro semanas antes do vencimento do contrato, um forte movimento de aumento do diferencial de bases, similar ao da semana do vencimento do contrato.

- As simulações utilizando contratos com vencimento em maio para realização de hedge, também de forma análoga ao exposto na Figura 4, revelam que quanto mais próximo do vencimento do contrato, menor o diferencial de bases. Tais resultados não corroboram as evidências de Zulauf et al. (1999) e Tomek \& Peterson (2001) de que há menores variabilidades quanto mais próximas do plantio.

- Já simulações utilizando contratos com vencimento em março apresentaram diferentes resultados para cada um dos municípios, conforme exposto na Figura 5.

Considerando a mudança do padrão de comportamento da base para a série com recorte entre 2015 e 2019, um recorte temporal nas séries das diferenças de base entre o período de 2009 a 2015 também foi realizado. Na Figura 6, é possível observar o resultado obtido nesse recorte temporal.

Inicialmente, é possível analisar que o comportamento das bases seguiu de forma muito similar o padrão da série de diferenças de base da Figura 4 (para 2009-19), em que simulações 
$2009-2015$

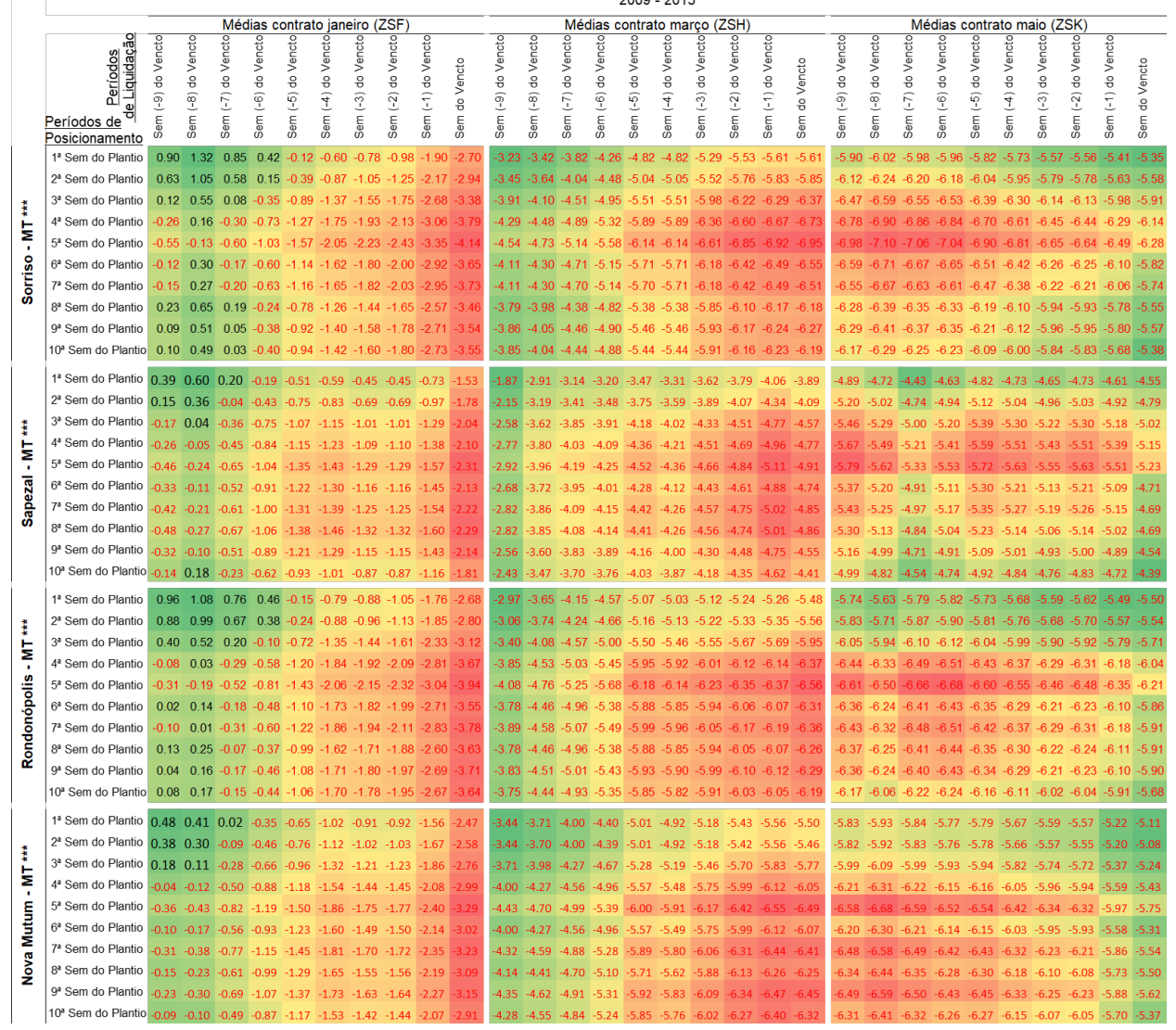

Figura 6. Diferenças de bases médias estratificadas por contrato - Horizonte temporal de 2009 a 2015. *** Horizonte temporal de 2009 a 2015. Fonte: consolidação de dados. Elaboração própria.

utilizando contratos com vencimento em janeiro e março evidenciam aumento da diferença de bases, assim que o vencimento do contrato se aproxima, e simulações realizadas utilizando contrato de maio expressam redução do diferencial de bases à medida que a maturidade do contrato se aproxima. Logo, após análise dos recortes das séries, é possível afirmar que há uma mudança de padrão de comportamento do diferencial da base entre os períodos de 2009 a 2015 e 2015 a 2019.

Visando identificar se os agentes que realizaram as operações de hedge, em média, incorreram em redução de seu faturamento em detrimento do custo de oportunidade, os diferenciais médios das bases foram sintetizados em um único valor médio por contrato para cada município objeto deste estudo, considerando os três horizontes temporais analisados anteriormente. A Tabela 1 contempla os resultados obtidos por meio dessa análise.

De forma unânime, nas simulações, os agentes que realizaram operações de hedge para se proteger dos riscos de oscilação de preços entre 2009 a 2019, em média, apresentaram redução de receita. O valor da redução, em média, foi algo entre US\$ 0,74 e US\$ 6,23 por saca, tendo as reduções mais significativas ocorrido durante o período entre 2009 e 2015, principalmente para aqueles agentes localizados no município de Sorriso que utilizaram contrato futuro com vencimento em maio como derivativo para realização das operações de hedge. 
Tabela 1. Média das diferenças das bases por contrato x município (US\$ por saca de 60 kg)

\begin{tabular}{|c|c|c|c|}
\hline \multirow{2}{*}{ Município } & \multicolumn{3}{|c|}{ Resultados sem recortes de 2009 a 2019} \\
\hline & Janeiro (F) & Março (H) & Maio (K) \\
\hline Sorriso $(\mathrm{MT})^{\star}$ & $-1,23$ & $-4,11$ & $-4,47$ \\
\hline Sapezal (MT)* & $-0,90$ & $-2,81$ & $-3,34$ \\
\hline Rondonópolis (MT)* & $-1,36$ & $-4,09$ & $-4,44$ \\
\hline Nova Mutum (MT)* & $-1,20$ & $-4,10$ & $-4,33$ \\
\hline Querência (MT)** & $-1,03$ & $-1,45$ & $-1,49$ \\
\hline \multirow{2}{*}{ Município } & \multicolumn{3}{|c|}{ Resultados com recorte de 2015 a 2019} \\
\hline & Janeiro (F) & Março (H) & Maio (K) \\
\hline Sorriso $(\mathrm{MT})^{\star \star}$ & $-1,33$ & $-2,19$ & $-1,84$ \\
\hline Sapezal $(\mathrm{MT})^{\star \star}$ & $-0,86$ & $-0,93$ & $-0,74$ \\
\hline Rondonópolis (MT)** & $-1,65$ & $-2,13$ & $-1,91$ \\
\hline Nova Mutum (MT)** & $-1,31$ & $-2,22$ & $-1,80$ \\
\hline Querência (MT)** & $-1,03$ & $-1,45$ & $-1,49$ \\
\hline \multirow{2}{*}{ Município } & \multicolumn{3}{|c|}{ Resultados com recorte de 2009 a 2015} \\
\hline & Janeiro (F) & Março (H) & Maio (K) \\
\hline Sorriso $(\mathrm{MT})^{\star \star \star}$ & $-1,16$ & $-5,33$ & $-6,23$ \\
\hline Sapezal $(\mathrm{MT})^{\star \star \star}$ & $-0,90$ & $-4,01$ & $-5,09$ \\
\hline Rondonópolis (MT) $)^{\star \star \star}$ & $-1,17$ & $-5,32$ & $-6,13$ \\
\hline Nova Mutum $(\mathrm{MT})^{\star \star \star}$ & $-1,20$ & $-5,29$ & $-6,01$ \\
\hline
\end{tabular}

Fonte: consolidação de dados. Elaboração própria.

* Horizonte temporal de 2009 a 2019. ** Horizonte temporal de 2015 a 2019. *** Horizonte temporal de 2009 a 2015. Estatísticas descritivas das séries estão no Apêndice 1 deste artigo.

Para o período compreendido entre 2015 e 2019, os impactos na redução de receita diminuíram substancialmente, apresentando redução média de receita entre US\$0,74 e US\$2,22 por saca. Ainda segundo a Tabela 1, as seguintes informações foram extraídas:

- As simulações de hedge utilizando contratos com vencimento em janeiro foram aquelas que apresentaram menos redução da receita por variação de bases, exceto para o município de Sapezal (contratos com vencimento em maio).

- No recorte de 2009 a 2015, contratos com vencimento em maio foram aqueles que apresentaram, em média, mais perda. Entretanto, no recorte de 2015 a 2019, foram as simulações utilizando contratos com vencimento em março que apresentaram mais redução de receita, exceto para Querência (contratos com vencimento em maio).

- De todos os municípios analisados, Sapezal foi aquele que chamou mais atenção. Em ambos os recortes temporais, as simulações para o município foram as que apresentaram menos redução de receita por diferencial de bases, especialmente no recorte de 2015 a 2019, período no qual a diferença de bases encontrada na simulação para o município chega a ser 1,5 vez menor do que o diferencial encontrado nas simulações para o município de Sorriso.

Diante dos resultados obtidos, foi possível concluir que houve um padrão de perdas, isto é, redução de receita, para os agentes que realizaram operações de hedge para comercialização de soja nos municípios de Nova Mutum (MT), Sorriso (MT), Rondonópolis (MT), Sapezal (MT) e Querência (MT), ao utilizarem como ativo subjacente contratos futuros comercializados na Bolsa de Chicago.

Maia \& Aguiar (2010) concluíram, para 2001 a 2004, que, em média, as operações de hedge de venda seriam mais adequadas se realizadas entre maio e novembro, enquanto as de compra, nos demais meses. Como o presente estudo não analisou contratos após maio, apenas é 
possível confirmar o padrão de perdas de base nos diferentes contratos. Por outro lado, para o período de 2005 a 2010, Medeiros et al. (2013) afirmaram que o sojicultor de Sorriso (MT) estaria mais sujeito a risco comparado ao de Rio Verde (GO).

Como muitas vezes se espera que a base permaneça em seus valores históricos, o presente estudo evidencia que isso não é verdadeiro, assim como citado por Taylor et al. (2004).

De maneira qualitativa, esse padrão de comportamento pode ser descrito da seguinte forma: para contratos com vencimento em janeiro e março, quanto mais próximo do vencimento do contrato, maior a diferença entre o preço futuro e o preço à vista das localidades analisadas, isto é, maior a diferença de bases. Já para aqueles com vencimento em maio, quanto mais próximo de vencimento do contrato, menor a diferença de bases.

Sob a perspectiva quantitativa, todos os municípios apresentaram redução de receita, sendo esta mais acentuada no período das simulações que compreende o horizonte temporal de 2009 a 2015. Para esse período, agentes que utilizaram contratos com vencimento em janeiro para realização do hedge de proteção de preços experimentaram, em média, reduções significativas de receita por saca de $60 \mathrm{~kg}$ - janeiro, US\$1,11, março, US\$ 4,99 e maio, US\$5,87. Embora reduzida, no recorte da série que compreende de 2015 a 2019, a receita dos agentes que lançaram mão dessa ferramenta, em média, sofreu reduções de US\$1,23 para contratos com vencimento em janeiro, US $\$ 1,79$ para aqueles com vencimento em março e US $\$ 1,56$ para aqueles com vencimento em maio.

Além da redução substancial das perdas de receita, evidenciada a partir de 2015, atenção especial deve ser concedida ao comportamento da base do município de Sapezal. Simulações realizadas no período de 2009 a 2015 evidenciam que para esse município a base sofre, em média, redução $60 \%$ menor do que a dos demais municípios. Tal situação fica ainda mais evidente durante as simulações realizadas no período de 2015 a 2019, quando a redução da base para Sapezal chega a ser, em média, 1,27 vez menor que a dos demais municípios.

\section{Considerações finais}

Calcado nos fundamentos teóricos de base e risco de base, hipótese Keynes e Hicks sobre preços futuros e normal backwardation, mercados eficientes e os trabalhos de Taylor et al. (2014), este trabalho analisa o comportamento da base ao longo de 2009 a 2019 para os municípios mato-grossenses de Nova Mutum, Sorriso, Rondonópolis, Sapezal e Querência.

Em primeiro lugar, os resultados revelam que a teoria de convergência entre preços futuros e preços à vista, à medida em que a maturidade do contrato se aproxima, não é uma realidade para a comercialização de soja nos cinco municípios analisados neste estudo. Ainda, tais resultados confirmam a afirmação de Keynes e Hicks sobre preços futuros de que os hedgers perderão dinheiro na média, estando mais predispostos a aceitar tal condição em busca de que os contratos futuros reduzam seu risco de comercialização.

Por meio deste estudo, foi possível observar que existe um padrão de perda, isto é, redução de receita para aqueles agentes que utilizam hedge como ferramenta de proteção contra o risco de preços nesses municípios. O presente estudo evidencia que a base não permanece em seus valores históricos, assim como citado por Taylor et al. (2004).

Sumariamente, esse padrão apresentou o seguinte comportamento:

- Para os contratos com vencimento em janeiro e março, quanto mais próximo do vencimento do contrato, maior a perda oriunda do diferencial de bases.

- Já para aquelas operações cujo ativo utilizado é o contrato com vencimento em maio, quanto mais próximo da maturidade do contrato, menor a perda por diferença de bases, 
diferentemente do risco de base obtido por Botelho Filho \& Souza Júnior (2006), calculado entre 2000 e 2005, em Lucas do Rio Verde e Sinop.

Sob a perspectiva quantitativa, os resultados revelaram que os agentes que realizaram operações de hedge para se proteger do risco de oscilação de preços entre 2009 a 2019, em média, apresentaram redução de receita entre US $\$ 0,86$ e US $\$ 6,23$ por saca, tendo as reduções mais significativas ocorrido durante 2009 a 2015, principalmente para aqueles agentes localizados no município de Sorriso, que utilizaram contrato futuro com vencimento em maio (ZSK) como derivativo para realização das operações de hedge. Para o período compreendido entre 2015 e 2019, os impactos na redução de receita diminuíram substancialmente, apresentando redução média de receita entre US\$ 0,74 e US\$2,22 por saca.

Ao realizar uma análise comparativa entre os municípios, Sapezal, para o período analisado (2009 a 2019), independentemente do contrato futuro utilizado para operação de hedge, apresentou as menores perdas por diferenças de base, seguido por Querência (2015 a 2019). Os demais municípios, em algum momento, apresentaram maior perda por diferencial de bases.

Por fim, diante do exposto ao longo deste trabalho, objetiva-se que os resultados oriundos dessa pesquisa contribuam, de maneira significativa, para futuros estudos de viabilidade econômico-financeira de quaisquer atividades relacionadas ao agronegócio mato-grossense, bem como para a orientação de agentes do agronegócio e entidades relacionadas, trazendo à luz os riscos inerentes às operações de proteção de preços para a cultura da soja, suas particularidades, seu funcionamento e sua efetividade.

Para futuros estudos, sugere-se avaliar a correlação entre variação cambial (dólares norte-americanos em comparação ao real) e variação da base; utilizar contratos futuros com diferentes vencimentos (julho, setembro e novembro) aos usados neste estudo para simulação das operações de hedge; analisar, de forma técnica, a razão pela qual o padrão de redução de receita em Sapezal (MT) é inferior ao dos demais municípios; verificar a efetividade de outras ferramentas para proteção de preços, como mercado a termo e opções.

\section{Referências}

Bekkerman, A., \& Pelletier, D. (2009, july 26-28). Basis volatilities of corn and soybean in spatially separated markets: the effect of ethanol demand. In Proceedings of the 2009 Annual Meeting. Milwaukee, Wisconsin: Agricultural and Applied Economics Association. Recuperado em 1 de fevereiro de 2020, de https://ideas.repec.org/p/ags/aaea09/49281.html

Botelho Filho, F. B., \& Souza Júnior, G. M. D. (2006). O risco de base para a soja em Sinop e Lucas, Mato Grosso. Revista de Política Agrícola, 15(4), 85-97.

Centro de Estudos Avançados em Economia Aplicada - CEPEA. (2019). Relatório PIBAgro - Brasil. Piracicaba-SP: ESALQ/USP. Recuperado em 18 de novembro de 2019, de https://www. cepea.esalq.usp.br/br/pib-do-agronegocio-brasileiro.aspx

CME Group. (2019). Oportunidades Únicas - O CME Group e a BM\&F Bovespa uniram-se para oferecer acesso global a dois dos mercados mais dinâmicos do mundo. Chicago: CME Group. Recuperado em 7 de outubro de 2019, de https://www.cmegroup.com/pt/files/ bmf-brazilian-prtnrshp-broch-port.pdf

Companhia Nacional de Abastecimento - CONAB. (2019). Série histórica das safras. Brasília: CONAB. Recuperado em 7 de setembro de 2019, de https://www.conab.gov.br/info-agro/ safras/serie-historica-das-safras?start $=20$ 
Cootner, P. H. (1960). Returns to speculators: Telser versus Keynes. Journal of Political Economy, 68(4), 396-404. Recuperado em 12 de julho de 2018, de http://www.journals.uchicago. edu/t-and-c

Feuser, C. E. (2014). Influência do risco de base na comercialização da soja em Mato Grosso (Dissertação de mestrado). Faculdade de Economia, Universidade Federal de Mato Grosso, Cuiabá.

Hennessy, D. A., \& Wahl, T. I. (1996). The effect of decision making on future price volatility. American Journal of Agricultural Economics, 78, 591-603.

Hicks, J. R. (1939). Value and Capital. Oxford: Clarendon Press..

Hull, J. C. (2012). Options futures and other derivatives (8th ed.). Boston: Prentice Hall.

Instituto Brasileiro de Geografia e Estatística - IBGE (2016). Produção agrícola municipal : culturas temporárias e permanentes. Rio de Janeiro: IBGE. Recuperado em 18 de Novembro de 2019, de https://www.ibge.gov.br/home/estatistica/economia/pam/2016/default.shtm.

Instituto Mato-Grossense de Economia Agropecuária - IMEA. (2017). Mapa das Macrorregiões do IMEA. Recuperado em 2 de dezembro de 2018, de http://www.imea.com.br/imea-site/ view/uploads/metodologia/justificativamapa.pdf

Keynes, J. M. (1930). A Treatise on Money. London: Macmillan.

Kolb, R. W. (1992). Is normal backwardation normal? The Journal of Futures Markets, 12(1), 75.

Maia, F. N. C. S., \& Aguiar, D. R. D. (2010). Estratégias de hedge com os contratos futuros de soja da Chicago Board of Trade. Gestão \& Produção, 17(3), 617-626.

Marques, P. V., Mello, P. D., \& Martines Filho, J. G. (2006). Mercados futuros e de opções agropecuárias. Piracicaba, SP: Departamento de Economia, Administração e Sociologia da Esalq-USP.

Mattos, F., \& Silveira, R. L. F. (2015). The effects of Brazilian Second (Winter) corn crop on price seasonality, basis behavior and integration to international market. In Proceedings of the NCCC-134 Conference on Applied Commodity Price Analysis, Forecasting, and Market Risk Management. St. Louis, MO: NCCC. Recuperado em 1 de fevereiro de 2020, de http://www. farmdoc.illinois.edu/nccc134

Medeiros, J. A. V., Cunha, C. A. D., \& Wander, A. E. (2013). Razão ótima de hedge para soja em Goiás e Mato Grosso. Revista de Política Agrícola, 22(1), 128-136.

Sanders, D. J., \& Baker, T. G. (2012). Forecasting corn and soybean basis using regime-switching models. In Proceedings of the NCCC-134 Conference on Applied Commodity Price Analysis, Forecasting, and Market Risk Management. St. Louis, MO: NCCC. Recuperado em 1 de fevereiro de 2020, de http://www.farmdoc.illinois.edu/nccc134

Stringer, C., \& Sanders, D. R. (2006). Forward contracting costs for Illinois corn and soybeans: Implications for producer pricing strategies. Journal of ASFMRA, 49-56.

Taylor, M., Dhuyvetter, K. C., \& Kastens, T. L. (2004). Incorporating current information into historical-average-based forecasts to improve crop price basis forecasts. In Proceedings of the NCR-134 Conference on Applied Commodity Price Analysis, Forecasting, and Market Risk Management. St. Louis, MO: NCCC. Recuperado em 29 de outubro de 2019, de http:// www.farmdoc.uiuc.edu/nccc134

Taylor, M., Tonsor, G., \& Dhuyvetter, K. (2014). Structural change in forward contracting costs for Kansas wheat. Journal of Agricultural and Resource Economics, 39(2), 217-229. 
Tomek, W. G., \& Peterson, H. H. (2001). Risk management in agricultural markets: a review. Journal of Futures Markets: Futures, Options, and Other Derivative Products, 21(10), 953-985.

United States Department of Agriculture - USDA. (2019). Foreign Agricultural Service. PS\&D - Production, Supply and Distribution. Washington, D.C.: USDA. Recuperado em 29 de outubro de 2019, de https://apps.fas.usda.gov/psdonline/app/index.html\#/app/advQuery

Waquil, P. D., Miele, M., \& Schultz, G. (2010). Mercados e comercialização de produtos agrícolas. Porto Alegre: Editora da UFRGS.

Working, H. (1949). The Theory of the Price of Storage. American Economic Review, 39, 1254-1262.

Zulauf, C. R., Irwin, S. H., Ropp, J. E., \& Sberna, A. J. (1999). A reappraisal of the forecasting performance of corn and soybean new crop futures. Journal of Futures Markets, 19(5), 603-618. 


\section{Material suplementar}

Este artigo acompanha material suplementar.

ARQUIVO SUPLEMENTAR com complemento metodológico, figuras auxiliares e tabela auxiliar.

Este material está disponível como parte da versão on-line do artigo na página: http:// www.scielo.br/resr

\section{Apêndice 1 - Gráficos e tabelas auxiliares}

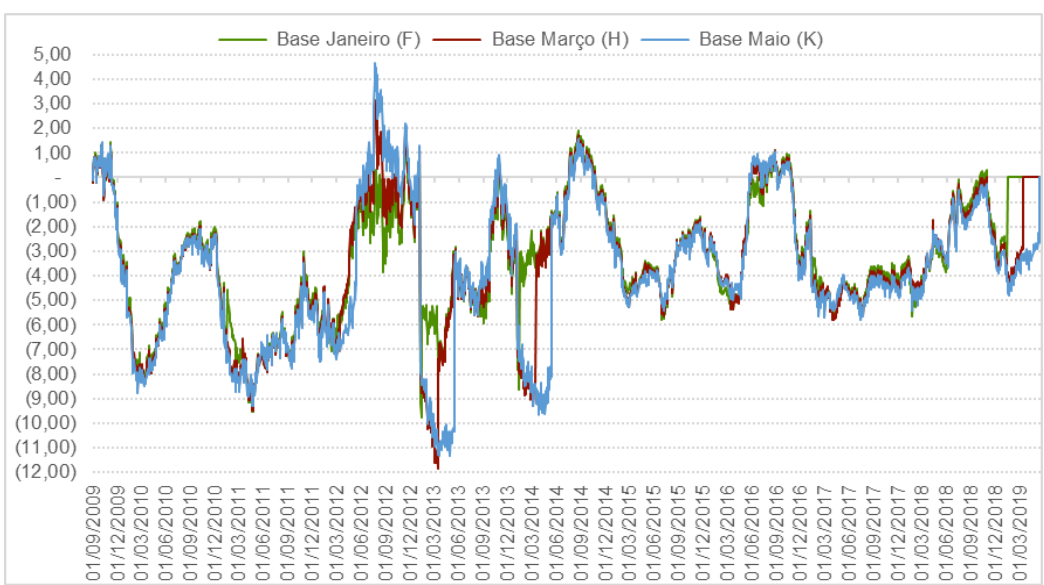

Figura A1. Evolução da base Nova Mutum em dólares (Spot Nova Mutum - MT x futuro CME). Fonte: dados consolidados. Elaboração própria.

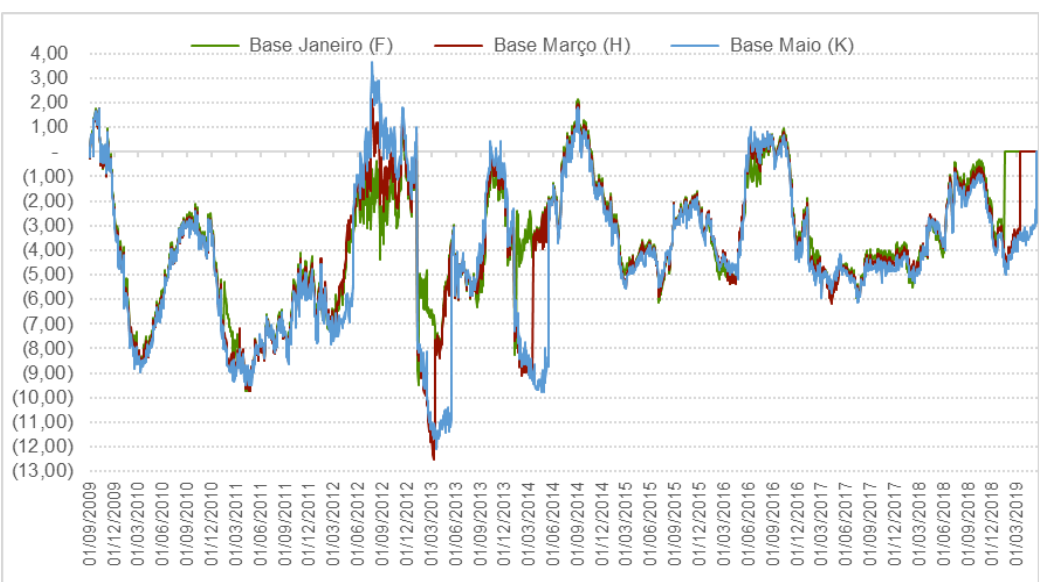

Figura A2. Evolução da base Sorriso em dólares (Spot Sorriso - MT x futuro CME). Fonte: dados consolidados. Elaboração própria. 


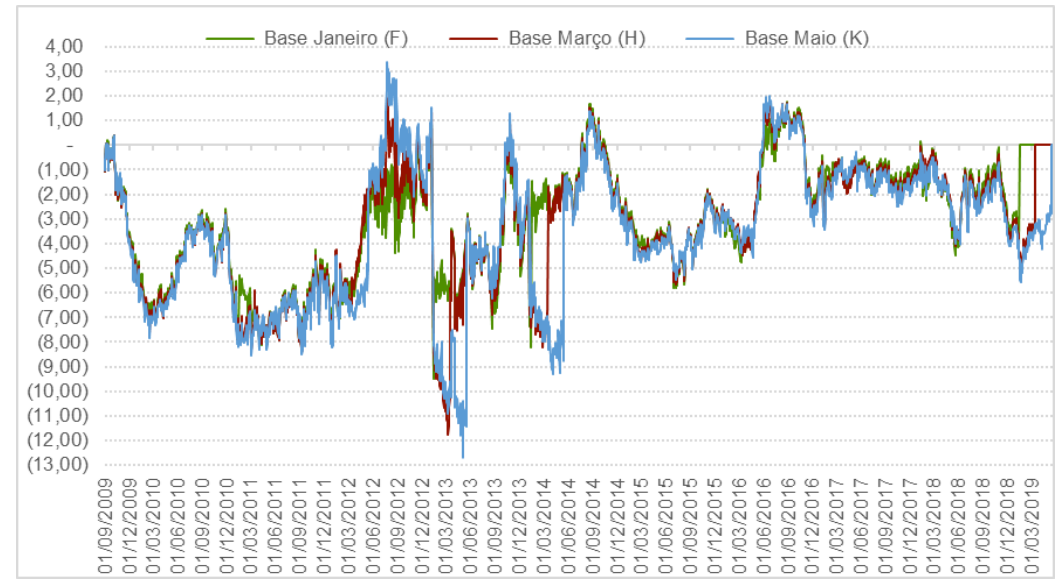

Figura A3. Evolução da base Rondonópolis em dólares (Spot Rondonópolis - MT x futuro CME). Fonte: dados consolidados. Elaboração própria.

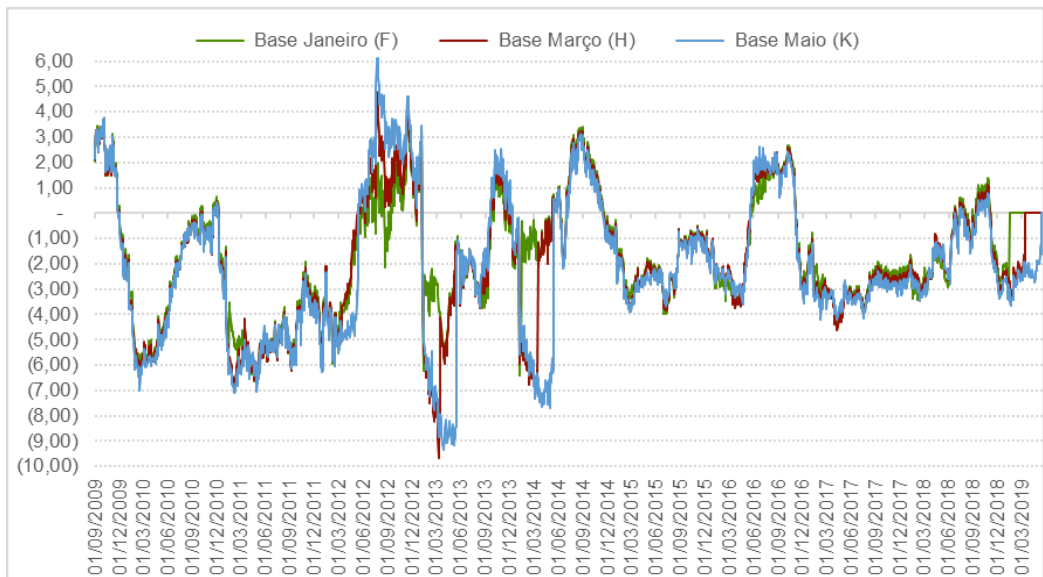

Figura A4. Evolução da base Sapezal em dólares (Spot Sapezal - MT x futuro CME). Fonte: dados consolidados. Elaboração própria.

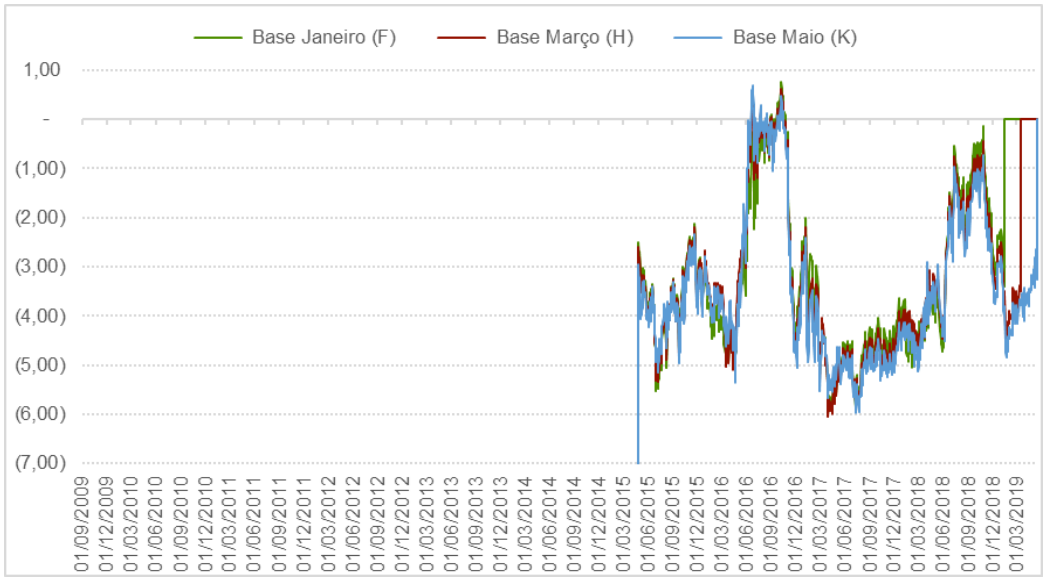

Figura A5. Evolução da base Querência em dólares (Spot Querência - MT x futuro CME). Fonte: dados consolidados. Elaboração própria. 
Tabela A1. Correlações entre os preços domésticos das diferentes localidades, 2009-2019, Mato Grosso

\begin{tabular}{cccccc} 
& Sorriso & Sapezal & Rondonópolis & Nova Mutum & Querência \\
\hline Sorriso & 1.000000 & 0.784935 & 0.986401 & 0.997094 & 0.969885 \\
Sapezal & 0.784935 & 1.000000 & 0.827553 & 0.792148 & 0.804905 \\
Rondonópolis & 0.986401 & 0.827553 & 1.000000 & 0.984741 & 0.968701 \\
Nova Mutum & 0.997094 & 0.792148 & 0.984741 & 1.000000 & 0.969914 \\
Querência & 0.969885 & 0.804905 & 0.968701 & 0.969914 & 1.000000 \\
\hline
\end{tabular}

Fonte: elaboração própria com dados da pesquisa.

Tabela A2. Estatísticas descritivas da diferença das bases entre semanas de plantio e colheita, 2009-2019, Mato Grosso

\begin{tabular}{cccccccccc} 
Contrato & Local & $\begin{array}{c}\text { Núm. de } \\
\text { obs. }\end{array}$ & Média & $\begin{array}{c}\text { Desvio } \\
\text { padrão }\end{array}$ & Mediana & Mínimo & Máximo & Simetria & Curtose \\
Janeiro & Sorriso & 100 & -1.23 & 0.8988 & -1.19 & -3.36 & 0.57 & -0.2024 & -0.6043 \\
Janeiro & Sapezal & 100 & -0.90 & 0.6287 & -0.99 & -2.31 & 0.60 & -0.0322 & -0.3367 \\
Janeiro & Rondonópolis & 100 & -1.36 & 0.8735 & -1.38 & -3.36 & 0.33 & -0.2048 & -0.6295 \\
Janeiro & Nova Mutum & 100 & -1.20 & 0.8980 & -1.19 & -3.29 & 0.48 & -0.3552 & -0.3989 \\
Janeiro & Querência & 100 & -1.03 & 0.3948 & -1.02 & -1.73 & -0.14 & 0.1420 & -0.6929 \\
Março & Sorriso & 100 & -4.11 & 0.7015 & -4.23 & -5.52 & -2.40 & 0.3757 & -0.6643 \\
Março & Sapezal & 100 & -2.81 & 0.4441 & -2.90 & -3.70 & -1.38 & 0.7752 & 0.7189 \\
Março & Rondonópolis & 100 & -4.09 & 0.6056 & -4.19 & -5.27 & -2.42 & 0.6194 & -0.0857 \\
Março & Nova Mutum & 100 & -4.10 & 0.6253 & -4.23 & -5.19 & -2.53 & 0.5475 & -0.5641 \\
Março & Querência & 100 & -1.45 & 0.3323 & -1.52 & -2.00 & -0.33 & 0.7937 & 0.2613 \\
Maio & Sorriso & 100 & -4.47 & 0.3907 & -4.49 & -5.22 & -3.45 & 0.2921 & -0.4538 \\
Maio & Sapezal & 100 & -3.34 & 0.2718 & -3.40 & -3.82 & -2.48 & 0.6811 & 0.0461 \\
Maio & Rondonópolis & 100 & -4.44 & 0.3182 & -4.53 & -4.96 & -3.48 & 0.5674 & -0.3169 \\
Maio & Nova Mutum & 100 & -4.33 & 0.3772 & -4.39 & -4.91 & -3.39 & 0.6243 & -0.3941 \\
Maio & Querência & 100 & -1.49 & 0.2933 & -1.53 & -1.97 & -0.59 & 0.7717 & 0.1955 \\
\hline
\end{tabular}

Fonte: elaboração própria. Dados da pesquisa. 